\title{
Anthropogenic Mineral Supply through a Circular Economy Approach Has Potential to Meet Chinese
}

\section{Resource Consumption}

Xianlai Zeng ${ }^{1,2}$, Saleem H. Ali, ${ }^{3,4}$, Jinping $\operatorname{Tian}^{1}$ and Jinhui $\mathrm{Li}^{* 1}$

${ }^{1}$ State Key Joint Laboratory of Environment Simulation and Pollution Control, School of Environment, Tsinghua University, Beijing 100084, China.

${ }^{2}$ Center for Industrial Ecology, School of Forestry and Environmental Studies, Yale University, New Haven, Connecticut 06511, United States.

${ }^{3}$ Energy and Environmental Policy Program, University of Delaware, Newark, DE 19709, United States. ${ }^{4}$ Sustainable Minerals Institute, University of Queensland, Brisbane 4072, Australia.

Correspondence and requests for materials should be addressed to J.L. (email: jinhui@tsinghua.edu.cn)

Abstract: An increasingly large quantity of primary mineral resource is being converted into manufactured products and destined for solid waste disposal. This material can be reclassified as "anthropogenic mineral reserves" and be a potential source of metals for a range of manufacturing uses. China is implementing a range of policy interventions which can lead to such a classification that will raise the profile of recycling programs as a means of metal supply. China is not only a major producer of consumer products and importer of secondary metals, but also has a major urban infrastructure footprint. Here we consider three product groups, 30 products, and imports, and map the recycling potential of anthropogenic mineral and 23 types of the capsulated materials by targeting their evolution from 2010 to 2050. Total weight of anthropogenic mineral on average in China reached 39 Mt in 2010, but it will double in 2022 and quadruple in 2045. Stocks of precious metals and rare earths will increase faster than most base materials. The total economic potential in yearly-generated anthropogenic mineral is anticipated to grow markedly from 100 billion US\$ in 2020 to 400 billion US\$ in 2050. Anthropogenic mineral of around 20 materials will 
be able to meet projected consumption of three product groups by 2050 , due to high availability of recycled content and gradual saturation of consumption. Durability of material usage and the concomitant stock of the anthropogenic mineral remain major challenges in determining the viability of this supply in the second half of the coming century.

Keywords: Anthropogenic mineral; Recycling; Circular economy; Metals; Urban mining 
There is wide recognition that humans have indelibly affected planetary processes to merit current times being termed "the Anthropocene"1,2 The recent rapid expansion of high-tech industries ${ }^{3,4}$, along with manufacturing innovations and consumer demand, have revolutionized societal investments in infrastructure for networking and for the rapid expansion of international commerce. However, the shortening useful life expectancy of the product, driven by rapid innovation, miniaturization and affordability, and an increasingly anthropogenic metabolism have led to a major increase in the accumulation of waste product, which could potentially be classified as "anthropogenic mineral" (AM, some relevant terminologies definition and boundaries are provided in Supplementary Information Section 1). ${ }^{3,5}$ One such waste stream is strictly regulated by the Chinese government. It is referred to as AM and was defined by the National Development and Reform Commission in 2010 to comprise the iron, non-ferrous metals, precious metals, plastic, or rubber material found within three waste products: electrical and electronic equipment (EEE, all the abbreviations and acronyms are also provided at Supplementary Information Section 2), vehicle, and wire \& cable. ${ }^{6,7}$ These are identified as the core scope of AM not only in China, but also in many industrial nations. $8,9,10,11$

Critical raw materials have also been sinking into AM reserves, while accelerating the depletion of virginal minerals. ${ }^{12,13,14,15}$ On the other hand, China is not only the world's major manufacturing power, but also one of the largest consumers and exporter of products. ${ }^{16}$ Nowadays China has all types of industries in UN International Standard Industrial Classification System and led in 220 products yields of global over 500 industrial products. ${ }^{17}$ China in recent years was also the largest importer of secondary resource to alleviate domestic material scarcity. Such features could highlight the unique opportunity for China to measure the potential of AM supply. ${ }^{18,19}$

EEEs and vehicles are the most fashionable aspiration of assets in Chinese households, which are the hallmark of the "Four Big Items" that consumers are aspiring towards (see Supplementary Figs. 3 and 4). Their rapid evolution and popularity since the 1970s have led to a dramatic rise in waste generation and resource consumption. The consumption of some mineral resources has gone through multiple increases ${ }^{20}$, resulting in a shortage of important strategic resources and a growth 
of external dependence. ${ }^{21,22,23}$ To meet future resource consumption, mining from AM has become a global concern and led to the popularization of the concept of a "circular economy".

How to measure the quantity of AM and its role in future resource supply is still a crucial scientific challenge. Basic AM information-including generation amount, composition, and resource transfer-is imperative to formulate effective governmental policies for the recycling industry. At least two gaps can be found in previous studies. Since waste electrical and electronic equipment (WEEE or e-waste), end-of-life vehicle (ELV), and waste wiring and cable (WWC) can mainly constitute an AM, there is no publication to comprehensively address the quantity and quality of China's AM reserve. Regarding e-waste, Zeng et al. (2016) firstly measured the quantity and quality, and uncovered China's recycling potential using material flow analysis and the lifespan model of the Weibull distribution. ${ }^{24}$ For ELV, van Schaik and Reuter defined the obsolescence rate and recycling rate in the $\mathrm{EU}^{25}$ and Field et al. (2017) initialed a comprehensive assessment of strategic and minor metals use for passenger cars and light trucks. ${ }^{26}$ Xue et al. (2013) established the model of material metabolism from manufacturing, consuming, and discarding, and indicated the recycling potential of ELV in China. ${ }^{27}$

The generation and quantity of $\mathrm{AM}$ are subject to urban metabolism affected by a variety of regulations, resultant policy, and technological change. ${ }^{28,29}$ The intertwined nexus among natural, social, and economic perspectives ${ }^{30,31}$ reveal that the accurate estimation of AM is very tough. No detailed studies are found on the total amount of current and anticipated AM. Furthermore, the dynamic transfer of existing resources from in-use stock to waste increases both the need for, and possibility of, sustainable resource harvesting from $\mathrm{AM}^{32,33,34}$ Therefore, we seek to uncover the mechanism of urban metabolism for e-waste, ELV, and WWC, comprehensively discover the recycling potential of $\mathrm{AM}$, and demonstrate their potential to meet future resource consumption. To complete this study, four procedures are employed: data collection for the consumption, importation, exportation, and material composition of AM; method development based on material flow analysis (MFA) and urban metabolism; generation estimation of AM quantity, and resultant economic potential; and validation of results using comparison with previous studies or reported data, sensitivity analysis, and uncertainty analysis (Supplementary Figs. 5 \& 7). 


\section{Methods}

Data collection. To discover the recycling potential of AM, we collected all available data needed for this study and substantially consolidated them, including:

- Detailed classification of EEE, vehicle, and wiring and cable in the AM (Supplementary Fig. 6),

- Statistics of domestic production for EEE, vehicle, and wiring and cable in China for 1990-2016 (Supplementary Table 1),

- Statistics of importation and exportation of EEE, vehicle, wiring and cable, e-waste, metal scraps, waste plastics for 1990-2016 (Supplementary Table 2),

- The weight ranges and those data distributions of each WEEE, ELV, and WWC determined from large samples (Supplementary Table 3),

- The average content of specific resources without any prejudice in a typical AM (Supplementary Tables 4 and 5), and uncertainty rates of all the content are estimated as no more than $20 \%$ and obey normal distribution ${ }^{35,36}$, and

- The market prices of the resources contained in the AM (Supplementary Table 6).

We collected the global available data and found that the average life spans of private passenger vehicles, government and business vehicles, non-operating buses, heavy duty, medium duty and light duty trucks are 14.5, 13.1, 11.5, 12.8, 10.1, and 8 years, respectively (Supplementary Table 14). Average life spans of taxis, transit buses and non-transit operating buses are 5,9 , and 5.5 years with the pattern of mandatory scrappage. ${ }^{37}$

Material flow analysis framework. More than ten methods or models have been adopted for AM estimation in previous studies, including the basic market supply ${ }^{38}$, the market supply method $\mathrm{A}^{39}$, the Stanford method ${ }^{40}$, the Carnegie Mellon method ${ }^{41}$, the material flow analysis ${ }^{42}$, time-series models $\mathrm{s}^{38}$, and stock-based models $\mathrm{s}^{43}$ (Their applications and difference can be seen in Supplementary Tables 8 and 9). The selection of a particular method depends mainly on data availability and robustness. ${ }^{44,45}$

In any socio-economic system, products flow into the society (sales), then accumulate in the built environment (stock); when reaching end of life (EoL) after a certain period (lifespan), they flow out as an $\mathrm{AM}^{46}$ Material flow analysis models quantitatively describe the dynamics, magnitude and interconnection of product sales, stocks and lifespans. ${ }^{47,48,49}$ Along this flow, China's AM can be sourced both domestically consumed products and imported waste (Supplementary Fig. 7). Domestic AM yield is attributed to products' manufacturing, exportation, and importation. Therefore, total weight of the AM can be defined by

$$
T(x)=D(x)+I^{\prime}(x)
$$


Where $T(x)$ is total China's AM by weight (in ton, 1 ton $=1000 \mathrm{~kg}$ ), $x$ is the year; $D(x)$ is domestic AM weight (in ton), and $l^{\prime}(x)$ is imported AM weight (in ton).

Data regression. We chose a stock-based model ${ }^{50,51}$ to define the net production of EEE, vehicle, wiring and cable. The net production of any given products from Eq. 1 was assumed to be both consumed and discarded in China, and its future demand was then determined using a time-step method based on data regression. Ideally, the Logistic equation is the feasible to enable the forecasting future demand. It is characterized of the rapid growth at the start stage, stable growth at the middle stage, and slow growth for a constant at the late stage, which is approximately expressed by exponential function, linear function, and constant value, respectively. Additionally, the decline of production and consumption commonly occurs while the product is replaced.

Weibull lifespan curve. Although products updating and consumer lifestyles can affect the utilization of products, ${ }^{52,53}$ the theoretic lifespan of products relies on the fatigue of the component materials subject to utilization ${ }^{54}$. The Weibull curve is sophisticated to depict the relationship between endurable fatigue and life time (or cycles to failure). ${ }^{54}$ Accordingly, the Weibull statistical distribution was chosen for this study to model the lifetime of product. For no regulated-lifespan products like EEEs and bicycle, the probability density function (PDF) of the Weibull distribution is given by Eq. $2^{51,55}$ Regarding the regulated-lifespan products like vehicle, and wiring and cable, the regulated lifespan should be considered and embedded into the conventional PDF for Eq. 3.

$$
\begin{aligned}
& f(x)= \begin{cases}\frac{\beta}{\eta}\left(\frac{x}{\eta}\right)^{\beta-1} e^{-(x / \eta)^{\beta}} & x \geq 0 \\
0 & x<0\end{cases} \\
& f(x)= \begin{cases}0 & x>L \\
e^{-(x / \eta)^{\beta}} & x=L \\
\frac{\beta}{\eta}\left(\frac{x}{\eta}\right)^{\beta-1} e^{-(x / \eta)^{\beta}} & 0 \leq x<L \\
0 & x<0\end{cases}
\end{aligned}
$$

The cumulative distribution function (CDF) for the Weibull distribution is ${ }^{56}$

$$
F(x)=1-e^{-(x / \eta)^{\beta}}
$$


where $\beta$ is the shape parameter $(\beta>0), \eta$ is the scale parameter $(\eta>0)$, and $L$ is the maximum lifetime of products regulated in China's legislation system (in year) (Supplementary Table 14). EoL units for a particular time $x$ can be mathematically described as ref. ${ }^{57}$. Eventually, the AM generation, resource stock, and meeting potential can be determined by the following equations: ${ }^{58,59}$

$$
\begin{gathered}
D(m)=\sum_{i=1}^{31} \int_{x 0}^{m} f_{i}(x) \cdot D_{i}^{\prime}(x) \cdot w_{i} \mathrm{~d} x=D(m)_{\mathrm{WEEE}}+D(m)_{\mathrm{ELV}}+D(m)_{\mathrm{wwC}} \\
=\sum_{i=1}^{15}\left[f_{i}(m-1990) \times D_{i}^{\prime}(1990)+f_{i}(m-1991) \times D_{i}^{\prime}(1991)+\mathrm{K}+f_{i}(1) \times D_{i}^{\prime}(m-1)\right] \\
+\sum_{i=1}^{15}\left[f_{i}(m-1991) \times D_{i}^{\prime}(1991)+f_{i}(m-1992) \times D_{i}^{\prime}(1992)+\mathrm{K}+f_{i}(1) \times D_{i}^{\prime}(m-1)\right] \\
+\left[f_{i}(m-1996) \times D_{i}^{\prime}(1996)+f_{i}(m-1997) \times D_{i}^{\prime}(1997)+\mathrm{K}+f_{i}(1) \times D_{i}^{\prime}(m-1)\right] \\
D^{\prime}(x)=P(x)-E(x)+I(x) \\
C(x)=D^{\prime}(x)-D(x) \\
D_{m, j}=\sum_{i=1}^{31}\left[\int_{x 0}^{m} f_{i}(x) \cdot D_{i}^{\prime}(x) \cdot w_{i} \mathrm{~d} x \cdot c_{i j}\right] \\
C_{m, j}=D_{m, j}^{\prime}-D_{m, j}=\sum_{i=1}^{31}\left\{\left[D_{i}^{\prime}(m)-D_{i}(m)\right] \cdot w_{i} \cdot c_{i j}\right\} \\
D^{\prime} \times 100=\frac{D}{D^{\prime}-D^{\prime}} \times 100
\end{gathered}
$$

where $m$ is the assigned year (2010-2050) for the concerned generation; $i$ is the $i^{\text {th }}$ category of product; 31 is total estimated categories for EEE, vehicle, and wiring \& cable; $x_{0}$ is the initial year of production ( $x_{0}=1990$ for EEEs, $x_{0}=1991$ for vehicle, and $x_{0}=1996$ for wiring \& cable); $D^{\prime}(x)$ is the demand quantity of product flow from production, exportation, and importation (in million or ton); $C(x)$ is the theoretical consumption of product (in million or ton); $w_{i}$ is the weight of $i^{\text {th }}$ category of each product (in $\mathrm{kg}$ or ton); $P(x)$ is the domestic production quantity (in million); $E(x)$ is the exportation of product (in million); /( $x$ ) is the importation of product (in million); $j$ is the $f^{\text {th }}$ resource category; $c_{i j}$ is the content of the $f^{\text {th }}$ resource in the $f^{\text {th }}$ category of products; $W_{m j}$ is the total weight of $f^{\text {th }}$ resource in the yearly-generated AM at the year of $m$ (in ton), which indicates the supply potential of AM; $C_{m j}$ is the total weight of $j^{\text {th }}$ resource in the consumption at the year of $m$ (in ton), and $M$ is defined as 
the meeting ratio of a certain resource supply from AM to the resource consumption from the three product groups (\%).

Sensitivity analysis. Demand prediction based on data regression, market price of materials, and importation of AM will be evaluated using sensitivity analysis because we only know their errors and ranges (Supplementary Tables 7 and 13). An incremental error for the future demand of EEEs, vehicle, and wiring \& cable is shown in Supplementary excel table. Correspondingly, the sensitivity using the feasible errors or ranges is indicated for the weight of AM and their materials. Importation is consisted of the legal importation for metals scrap (e.g., $\mathrm{Cu}, \mathrm{Al}$, and $\mathrm{Fe}$ ) and plastic scrap, and the illegal importation for toxic waste (e.g., e-waste). Those ranges will affect the uncertainty of total AM. High but known importation in recent year means high influence on total AM. However, the low range or error of importation in recent year means that it is not sensitive for share of importation. With the error increasing and urban mining growth, the biggest uncertainty occurred in 2023 when importation share ranges from $4 \%$ to $19 \%$. Later, rise of domestic AM and decline of importation result in that importation's biggest sensitivity imposed on total AM will drop to 10\% in 2030, and less than 4\% in 2050 (Supplementary Fig. 8a).

Uncertainty analysis. Both the method and the input data will affect the uncertainty of estimated results. The method, in particular from data regression, will be identified with the feasible error. The data including weight and average content will be assessed with uncertainty analysis. Here, a Monte Carlo simulation $\left(10^{5}\right.$ iterations) was conducted to obtain final estimates of flows and their uncertainties in this study. Based on the relevant collected data, and those distributions illustrated in Supplementary Tables 3, 4, and 14, uncertainties of total AM weight and yearly-added resource stock (e.g., Cu and Al) in 2017 \& 2030, for instance, are performed and presented in Supplementary Fig. 8b. Similarly, the resources stock from Monte Carlo simulation can also cover the forecasting results at the maximum probability interval.

\section{Results}

AM generation. We firstly pre-mined the available data for further estimation of domestic generation of AM: (1) Lifetime distribution function of all the relevant products is determined by Supplementary Text 3 and Table 15; (2) Dara regression is enabled with Supplementary Figs. 10-12 for the annual net production and imported scraps; and (3) the incremental error or range are configured for the estimation of future demand and importation (Supplementary excel table and Table 13). Accordingly, domestic generation of WEEE, ELV, and WWC are uncovered (Fig. 1a and 
Supplementary Fig. 13). The weight of WEEE on average was 4.67 million tons (1Mt $=1000 \mathrm{kt}=10^{6}$ tons) in 2010, but it will reach 27.22 Mt in 2030 and $51.60 \mathrm{Mt}$ in 2050. The distribution of WEEE types in China is also evolving through the period 2010-2050. In 2015, the four types, by weight, were AC, DPC, monitor, and RF, accounting for 73\% of the total WEEE. However, in 2020, the four types, by weight, will be DPC, AC, RF, and monitor, accounting for $76 \%$ of total WEEE. In addition, by 2030 , the four types are expected to be AC, DPC, RF, and WM, accounting for $81 \%$ of total WEEE. The weight share of the remaining WEEE types has been shrinking since 2010.

For ELV, a continued increase also can be found both in weight and in quantity (Fig. 1b and Supplementary Fig. 13). China has become the largest generator and seller of vehicle since 2009. In the end of 2015, China's total registered vehicle reached 279 million $(M)^{60}$, exceeding $264 \mathrm{M}$ of USA ${ }^{61}$. The total ELV reached 11.01 Mt in 2010, and three-fold rise will occur in 2017. Later, it will reach around $61.37 \mathrm{Mt}$ in 2030 and $97.10 \mathrm{Mt}$ in 2050. Thus, the average annual amount of ELV will be over $2 \mathrm{Mt}$ in 2010-2050. Among the main large ELV, the share in 2010 was nearly 54\%, 18\%, 9\%, 2\%, and 0 for $\mathrm{CT}, \mathrm{PV}, \mathrm{RV}$, tractor, and $\mathrm{EV}$, respectively. With respect to $\mathrm{WWC}$, those weights will remain under $5 \mathrm{Mt}$ before 2025, and then dramatically increase to $33 \mathrm{Mt}$ in 2040 (Fig. 1C).
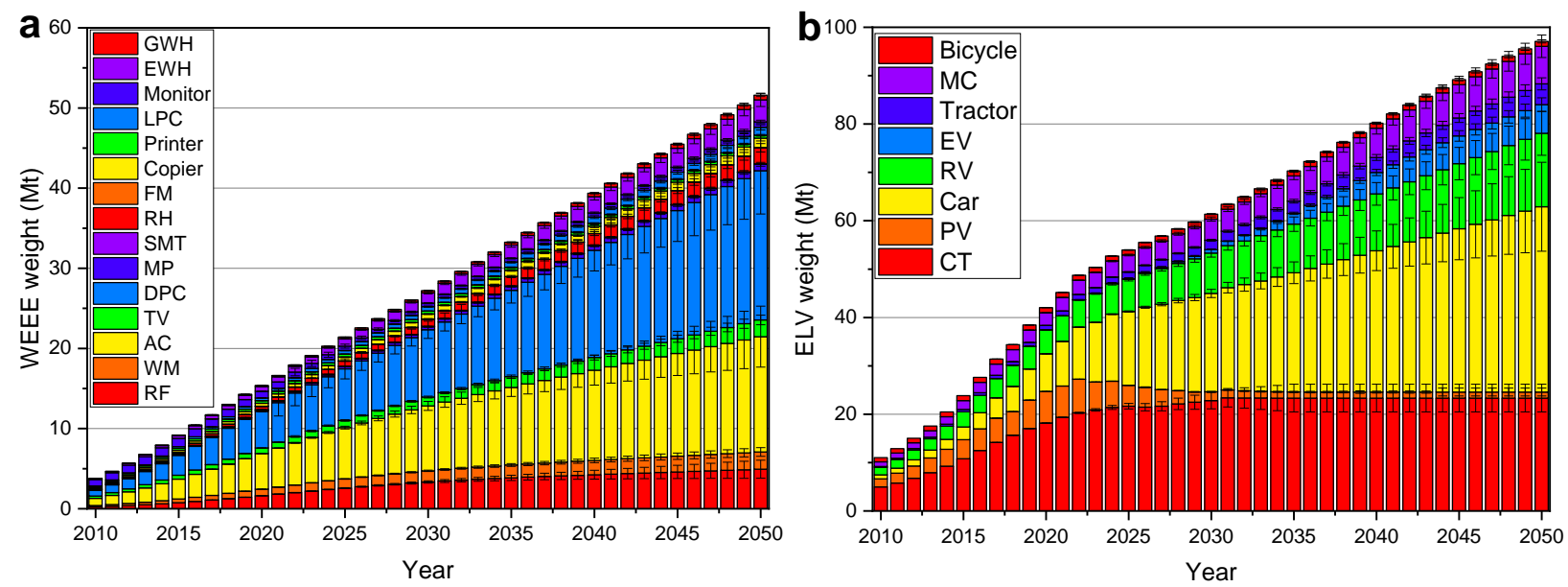

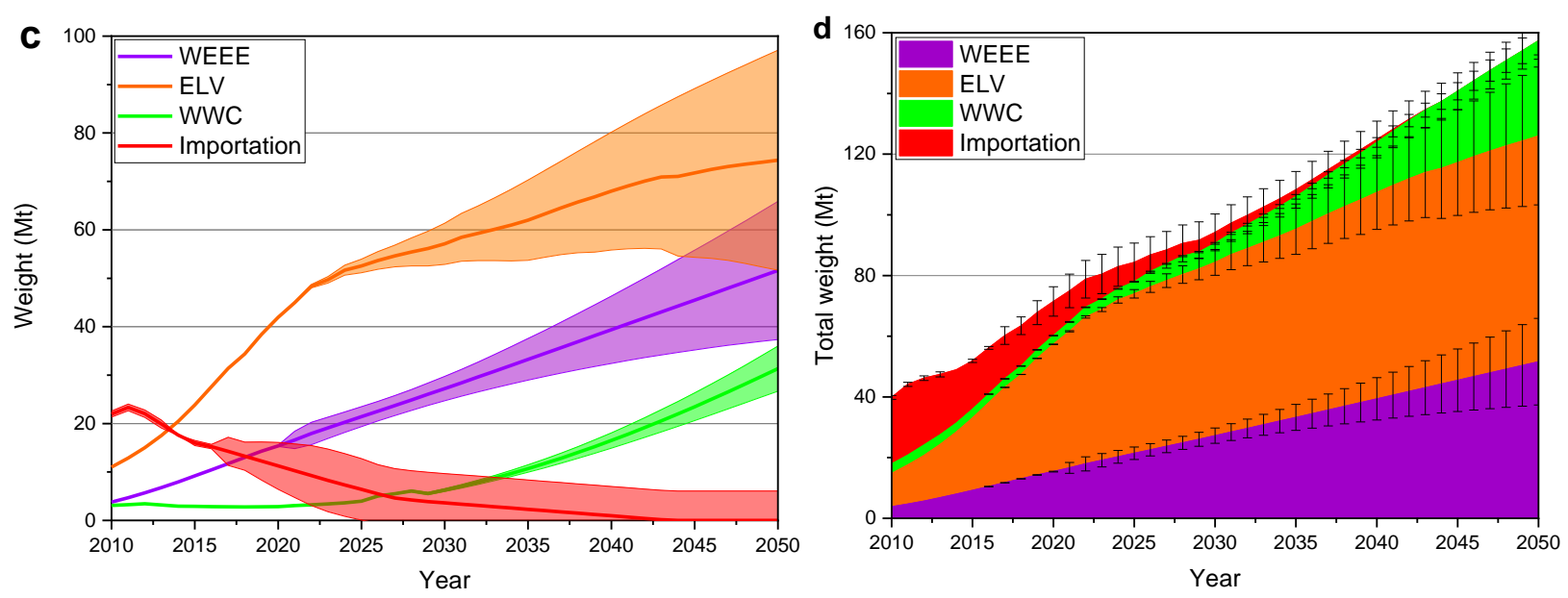

Fig. 1 Estimation of China's AM from 2010 to 2050: (a) WEEE weight; (b) ELV weight; (c) Weight range; (d) Total weight.

Regarding the importation, steel scrap, copper scrap, aluminum scrap, and plastics scrap are the majority of imported AM. In July 2017, China issued a rigorous policy of phasing out waste import, including some unrestricted import of waste (Supplementary Table 12). ${ }^{62}$ The linear fitting has been employed to model the imported e-waste and scraps from 2010 to 2050 (Supplementary Fig. 12 and Table 13). Illegal importation of e-waste will shrink and disappear in 2020s. The total importation of scraps was around 21 Mt in 2010, but will dramatically decrease to 1 Mt in 2040. In weight of imported scraps, plastics scrap is leading (verified by Brook et al' studies ${ }^{63}$ ), followed by steel scrap, copper scrap, and aluminum scrap (Fig. 2e).

Totally, the weight of the yearly-generated AM generation in China was estimated for 40 Mt in 2010. Driven by the large expansion of WEEE, ELV, and WWC, total generation weight will reach $71 \mathrm{Mt}$ in 2020, 101 Mt in 2030, and 176 Mt in 2050 (Fig. 1d). The average increasing amount in 2010-2050 will be 3.4 Mt per year, and over one half will be provided by ELV, thus ELV may impose more stresses and tensions on government and industry than WEEE and WWC in the future. In addition, importation will shrink when its share in total AM is cut down from 51\% in 2010 to 7\% in 2025 (Fig. 1b).

Evolution of valuable resources in AM. When some products reach their EoL, a large quantity of valuable resources is inevitably encased in $\mathrm{AM}^{64}$, regardless of whether in hibernating stock or not." ${ }^{65}$ The amount of encased eleven base materials (e.g., Cu, Al, Fe, Co, Pb, Zn, Sn, Mg, plastics, rubber, 
and glass), five precious metals (e.g., Au, Pd, Ag, Pt, and Rh), two rare metals (e.g., In and W), and five rare earths (including Nd, Dy, La, Y, and Eu) in yearly-generated AM can be easily determined (Supplementary Fig. 14). Almost all mineral resources encased in WEEE, ELV, and WWC have been constantly growing since 2010, and can be expected to continue to rise, at least until 2050.

Totally, for base materials, eight metals, except $\mathrm{Pb}$, maintain the increasing tendency despite of a rapid decline of importation. In 2010, the mineral resources of $\mathrm{Cu}, \mathrm{Al}, \mathrm{Fe}, \mathrm{Zn}, \mathrm{Co}, \mathrm{Sn}$, and Mg were approximately $7.03 \mathrm{Mt}, 4.46 \mathrm{Mt}, 14.69 \mathrm{Mt}, 0.78 \mathrm{kt}, 5.82 \mathrm{kt}, 0.16 \mathrm{kt}$, and $46 \mathrm{kt}$, respectively, but they will rise to $28.52 \mathrm{Mt}, 16.35 \mathrm{Mt}, 82.63 \mathrm{Mt}, 10.65 \mathrm{kt}, 23.49 \mathrm{kt}, 2.23 \mathrm{kt}$, and $441 \mathrm{kt}$ on average by 2050, respectively (Fig. 2). The amount of $\mathrm{Co}$ and Fe will lead in the increasing rate among all the base materials due to the dramatic and continuing boom of battery and vehicle. The popularity of display substitution and the build-up of vehicle, in particular used with lead-acid battery, have resulted in a peak of 4.3 Mt for Pb generation around 2020, verified by the previous studies ${ }^{66,67}$. Simultaneously, the amount of plastic, glass, and rubber will increase around 55\%-, 8-, and 7.7-fold from 2010 to 2050 (Fig. 2).
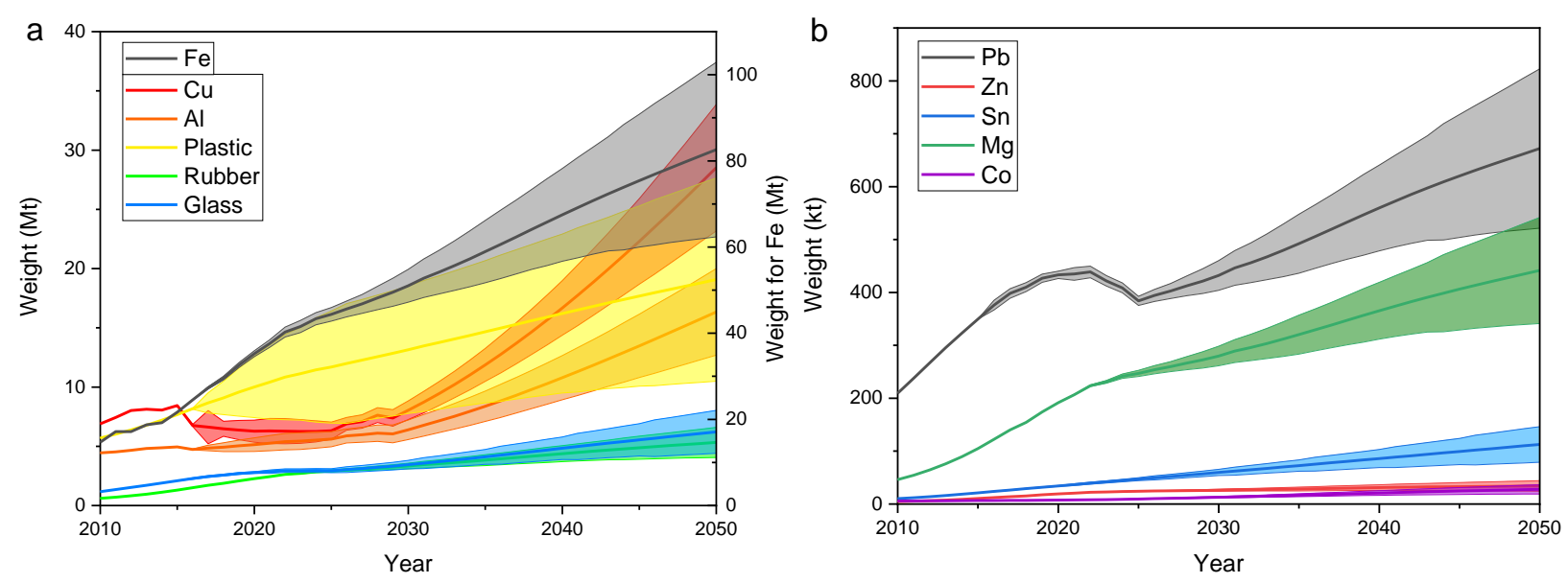

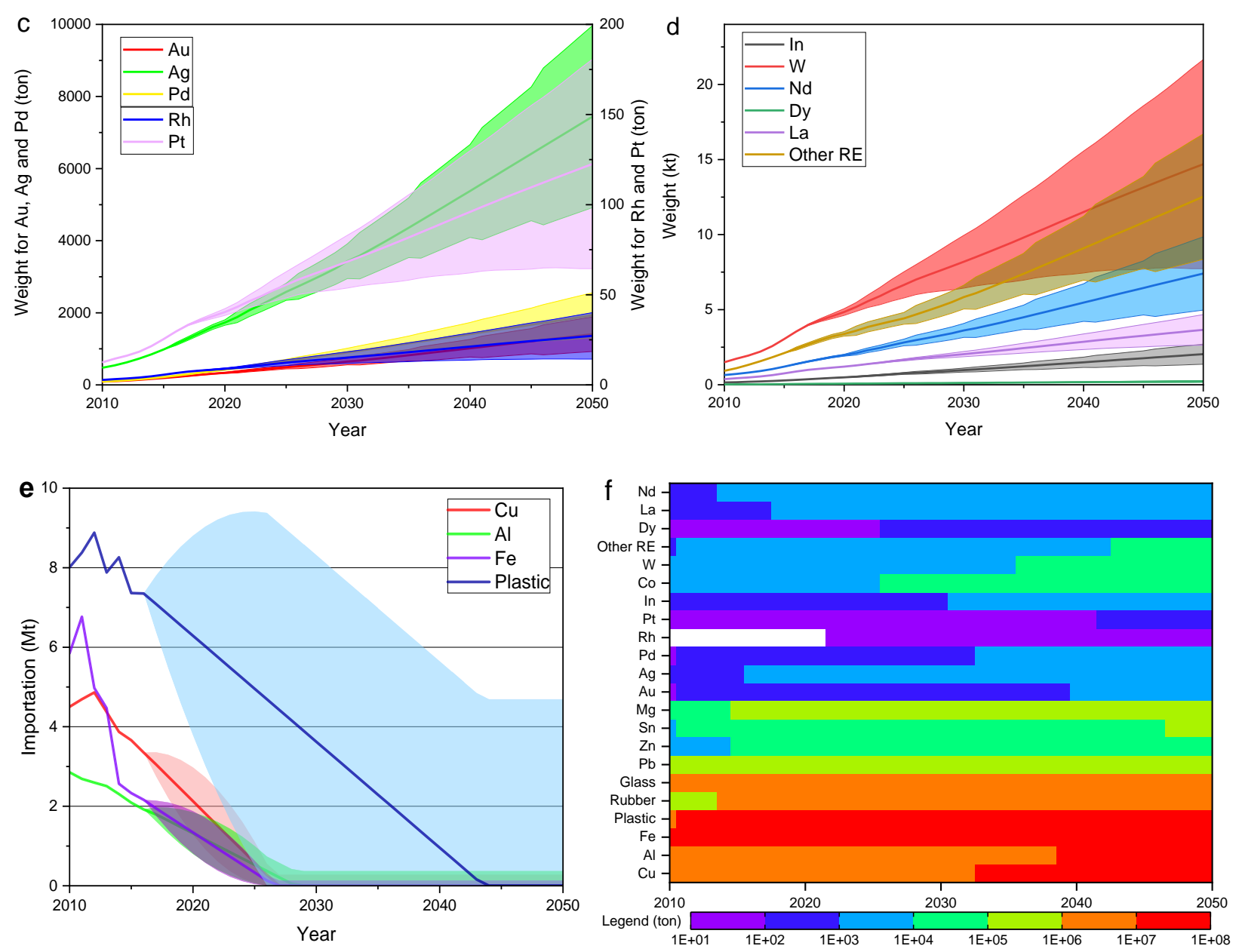

Fig. 2 Resources weight in yearly-generated AM: (a) base materials; (b) Pb, Zn, Sn, and Mg materials; (c) precious metals; (d) rare metals and rare earths; (e) imported resources; (f) average resource map.

The total precious metals are always keeping the growth trend in the year of 2010-2050. The amounts of $\mathrm{Au}, \mathrm{Pd}, \mathrm{Ag}, \mathrm{Rh}$, and Pt were only 89.95, 92.98, 473.84, 2.98, and 6.96 tons, respectively in 2010, but they will grow roughly 15-, 19-, 14-, 8-, and 8-fold in 2050 (Fig. 2c). Actually, around global 85\% Rh, 50\% Pd, and 43\% Pt were used in automobile catalyst scraps. ${ }^{68}$ The same ascending trend in total rare metals and rare earth remains as the other metals. The amounts were approximately $0.15 \mathrm{kt}, 26.75 \mathrm{t}, 0.44 \mathrm{kt}$, and $0.92 \mathrm{kt}$ for $\mathrm{In}, \mathrm{W}, \mathrm{Nd}$, and other rare earth, respectively, but they will rise to $2.04 \mathrm{Mt}, 366$ tons, 5.38 kt, and $12.52 \mathrm{kt}$ by 2050, respectively (Fig. 2).

Economic potential of AM. From an economic perspective, the huge amount of valuable resources capsuled in $\mathrm{AM}$ is also enhancing the recycling potential ${ }^{69}$. Despite of the large range imposed by market price of resource, the average of economic potential from urban mining has been evolving 
from roughly 74 billion US $\$$ in 2010, to an anticipated 170 billion US $\$$ in 2030 and 428 billion US $\$$ by 2050 (Fig. 3a). During the evolution of recycling potential until 2050, base materials and precious metals have the major economic potential. But the former will drop from 90\% in 2010 to around 70\% in 2030-2050, and the latter will sharply go up from 4\% in 2010 to 15\% in 2030-2050 (Supplementary Fig. 15). The remaining recycling potential is predominantly provided by rare metals. Furtherly, the highest-value materials—Cu metal—comprise averagely 40\%, followed by Au (5-18\%), In (4-13\%), Al $(8-13 \%), \mathrm{Pd}(2-11 \%)$, and plastic (5-10\%). As a result, $\mathrm{Cu}, \mathrm{Al}$, plastic, and $\mathrm{Au}$ is currently major recycling targets from $\mathrm{AM}$, but in the future $\mathrm{Cu}, \mathrm{Au}, \mathrm{In}$, and $\mathrm{Al}$ will become the crucial valuable materials (Fig. $3 b)$.
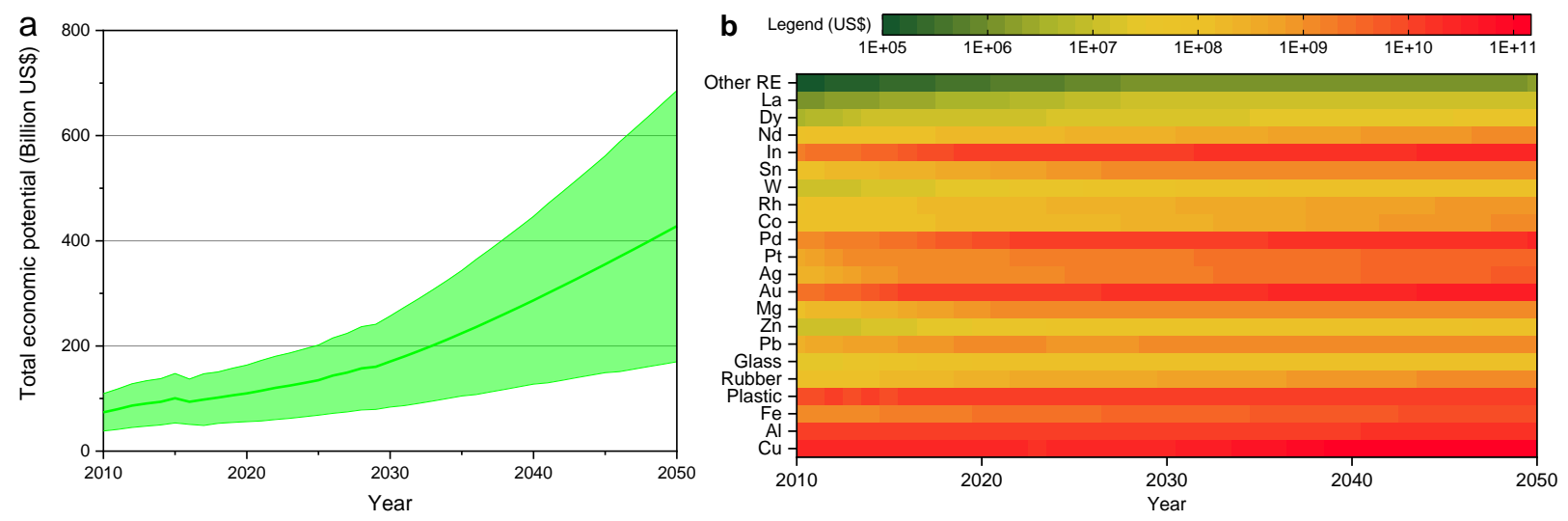

Fig. 3 Economic potential of AM: (a) economic value of total annual AM; (b) economic potential map of materials. Note: the shade of light blue indicates the range of recycling potential. The green, yellow, read, and purple indicate the shares for base materials, precious metals, rare metals, and rare earth, respectively. REs, other rare earth.

Meeting potential of AM supply for future resource consumption of three product groups. The future consumption of product is theoretically equal to net addition to in-use stock, which is the difference between the demand and the generated AM (Eq. 7 and Supplementary Fig. 2). All the relevant materials are also chosen to uncover the future resource consumption imposed by EEE, vehicle, and wire \& cable. $\mathrm{Cu}, \mathrm{Al}, \mathrm{Au}$, and Pd will maintain the growth until 2030 and afterwards reach the constant (Fig. 4), which is attributed to the flourish of wiring and cable and $\mathrm{EEE}^{70} . \mathrm{Pb}$ demand increased from 0.91Mt in 2000 to $7.75 \mathrm{Mt}$ in $2014^{66}$, but Pb, Fe, Zn, and rubber are quickly decreasing until 2020, and afterwards almost keep the unchanged range while vehicle and EEE are approaching 
the final saturation; Co will increase and reach the peak in 2030 because the cathode material in lithium-ion battery is gradually substituted from lithium cobalt oxide to lithium nickel cobalt aluminum oxide and lithium iron phosphate in electric vehicle and consumer electronics ${ }^{71}$; Other fifteen materials of future consumption have entered a stabilized phase. The plastic, for instance, will always maintain about $6 \mathrm{Mt}$ in 2010-2050 while the falling importation and the increasing production will mingle together.
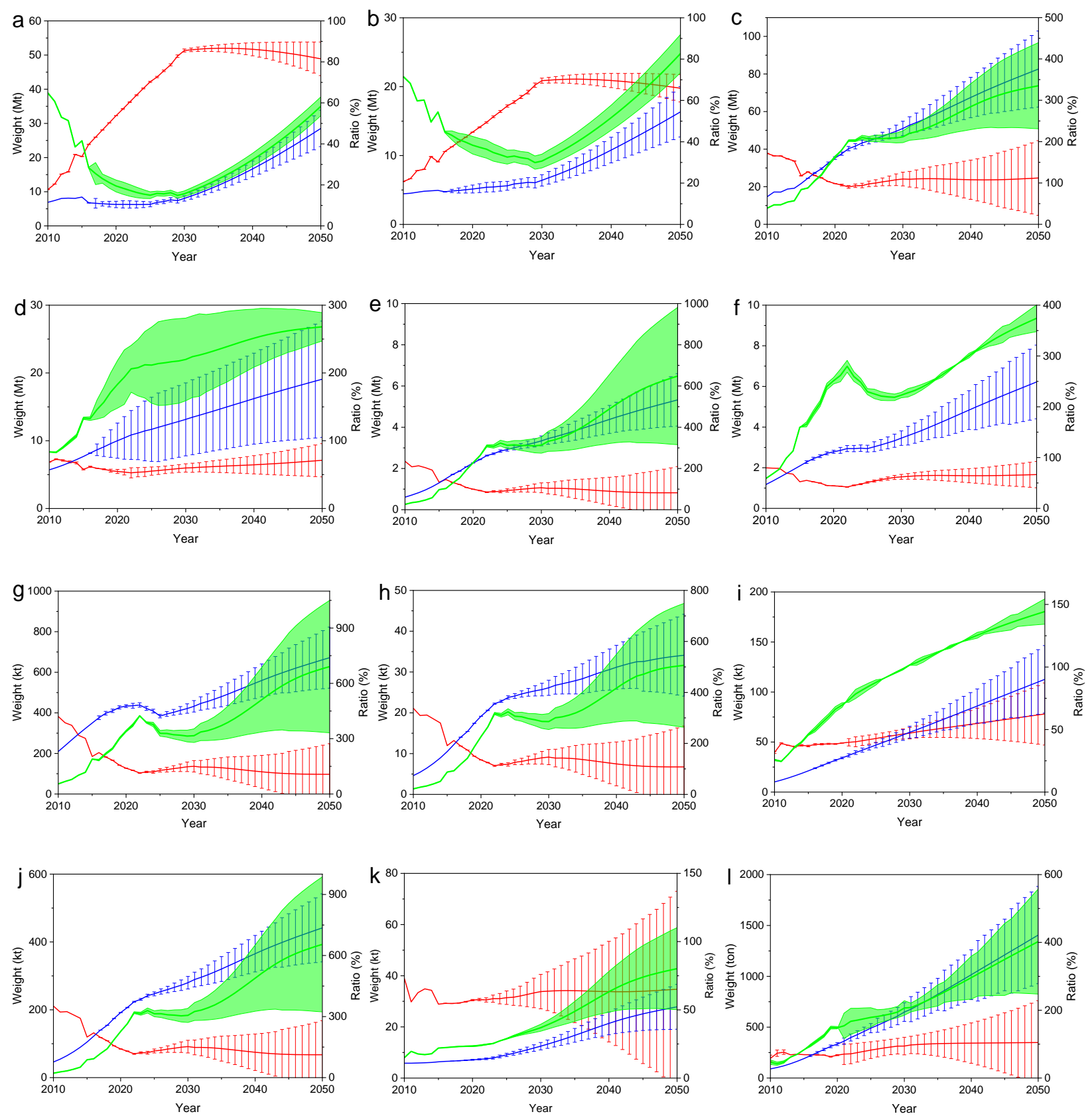

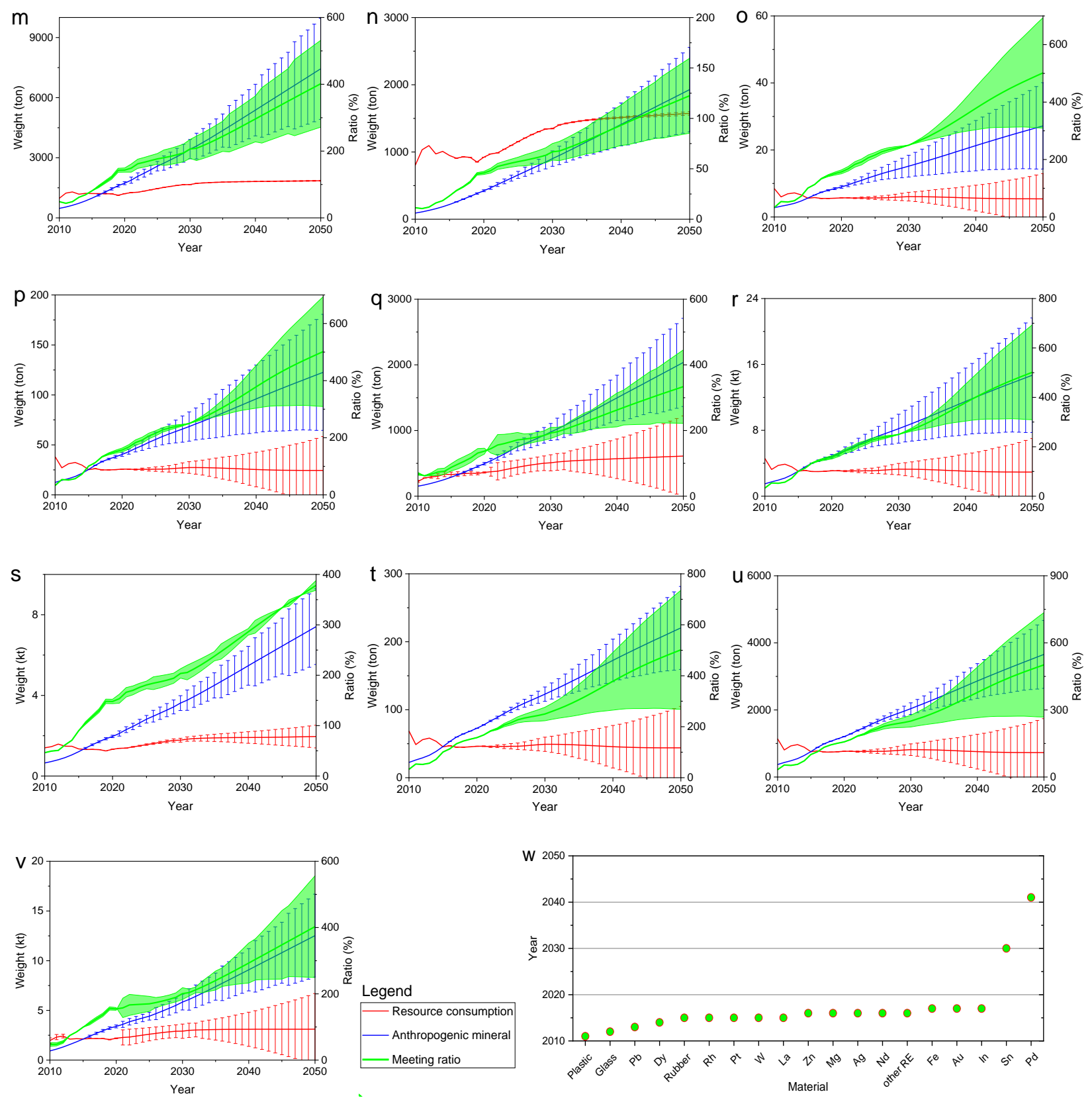

Fig. 4 Meeting potential of AM for resource consumption of three product groups: (a) Cu; (b) Al; (c) Fe; (d) Plastic; (e) Rubber; (f) Glass; (g) Pb; (h) Zn; (i) Sn; (j) Mg; (k) Co; (I) Au; (m) Ag; (n) Pd; (o) Rh; (p) Pt; (q) In; (r) W; (s) Nd; (t) Dy; (u) La; (v) other RE; (w) Meeting time of various materials.

We further uncover the supply potential of AM. With the dramatic rise of AM generation and the gradual saturation of material consumption, the potential supply from AM is becoming possible to overtake the resource consumption of three product groups (Fig. 4). Although we are currently still far from a closed-loop society owing to low recycling rate $^{72}$, a rapid advancement is indeed arising 
for regulation, policy, and technology of circular economy and urban mining. The highly-efficient collection and the cutting-edge recycling will significantly enhance the recycling rate in the future. Thus, if substantial recycling, eighteen materials of AM could meet their demand before 2020, and in 2050 they probably provide over two-folder consumption. The meeting time of Sn and Pd will be approximately 2030 and 2041, respectively. Although Cu, Al, and Co of AM cannot meet their potential consumption by 2050 , the disparity gap between their consumption and AM will be greatly reduced in the following decades. Consequently, AM supply has a growing potential to meet their future resource consumption.

\section{Discussion}

The detailed comparison indicated in Supplementary Information Section 4 can verify the results mentioned above, and further consolidate the relevant results (Fig. 1). China has already overtaken the U.S. to become the world's leading producer of e-waste. All types of cars in weight will exceed the $\mathrm{CT}$ and become the leading ELV in 20 years later. In quantity, MC, car, and EV still maintain a rapid increment until 2050. Other vehicles are moving towards saturation (Supplementary Fig. 13b). The evolution of WWC weight is subject to longer lifespan of wiring and cable than those of EEE and vehicle. Rapid urbanization and economic growth in 1980s-2010 will impose a significant influence after 2025. China has revised the standard of lifespan for wiring and cable from 20 years to 70 years, which can decline the obsolescence of wiring and cable. Lastly, the circular urged the related ministries and departments to continue cracking down on smuggling of dangerous trash, medical waste, e-waste, and household garbage (Supplementary Table 11). ${ }^{62,73}$ The importation of AM will fall dramatically so that there will perhaps be a couple of years for the whole disappear of importation (Fig. 2e).

Globally, Au, Ag, and In in remaining underground reserve can only sustain the future consumption for 36 years, 9 years, and 4 years at half of U.S. per capita consumption rates. ${ }^{74}$ Their exploration and mining will be far harder and more costly owing to the increasing depth of exploration and the

descending grade. ${ }^{75,76}$ Most anthropogenic base metal minerals have the higher grade and purity (as the pure metal or alloy) than the general natural minerals. Eventually, through a circular economy AMs will play an essential role for supply security and for overall sustainability objectives. China's 
focus will be shifting from the dependence of virgin mining and waste imports to domestic urban mining of AM.

Further, the following points could be also concerned: (1) Some specific uses of metals (e.g., indium ${ }^{77}$, aluminum $^{78}$ ) were more difficult to fully obtain from AM owing to their high dispersion or potential thermodynamic limit ${ }^{79}$. Luckily, continuous endeavors in regulation and technology related to ecodesign and the circular economy will hopefully ameliorate this situation; ${ }^{80}$ (2) Investing in research and infrastructure to allow for AM mining can be an effective approach to relieving this resource shortage bottleneck ${ }^{22,81,82}$. Meanwhile, the increase in the amount of AM, as shown by our data, suggests more economic viability in harnessing this reserve; (3) Last, the philosophy of "despising the poor and currying favor with the rich" (prefer to the high-grade mineral), is commonly taken during conventional virgin mining. ${ }^{83}$ But the environmental and social risks associated with harnessing AM should be fully considered while striving for "treasure" hunting. Both eyes should open for urban mining to reach the double sustainability of the environment and resource.

Reporting summary. Further information on experimental design is available in the Nature Research Reporting Summary linked to this article.

\section{Data availability}

The authors declare that the data supporting the findings of this study are available within the paper (and its supplementary information files).

\section{References}

1. Waters $\mathrm{CN}$, et al. The Anthropocene is functionally and stratigraphically distinct from the Holocene. Science 351, (2016).

2. Malhi Y. The Concept of the Anthropocene. Annu Rev Env Resour 42, 77-104 (2017).

3. Williams E. Environmental effects of information and communications technologies. Nature 479, 354-358 (2011).

4. Vidal O, Goffe B, Arndt N. Metals for a low-carbon society. Nature Geosci 6, 894-896 (2013). 
5. Baccini P, Brunner PH. Metabolism of the Anthroposphere: Analysis, Evaluation, Design. MIT Press (2012).

6. NDRC, MOF. Notice on Developing Urban Mining Demonstration Base Construction. (ed^(eds Resource DoEa). State Council (2010).

7. Zeng X, Li J. Urban Mining and Its Resources Adjustment: Characteristics, Sustainability, and Extraction. SCIENTIA SINICA Terrae 48, 288-298 (2018).

8. Cossu R, Williams ID. Urban mining: Concepts, terminology, challenges. Waste Management 45, 1-3 (2015).

9. Graedel T. The Prospects for Urban Mining. Bridge 41, 43-50 (2011).

10. Brunner PH. Urban Mining A Contribution to Reindustrializing the City. Journal of Industrial Ecology 15, 339-341 (2011).

11. Nakamura T, Halada K. Urban Mining Systems. Springer Japan (2015).

12. Allwood J, Cullen JM. Sustainable Materials: With Both Eyes Open. UIT Cambridge Ltd (2012).

13. Ali SH, et al. Mineral supply for sustainable development requires resource governance. Nature 543, 367-372 (2017).

14. IRP. Global Assessment of Natural Resource Use and Management. United Nations Environment Programme (2019).

15. Zheng X, Wang R, Wood R, Wang C, Hertwich EG. High sensitivity of metal footprint to national GDP in part explained by capital formation. Nature Geoscience 11, 269-273 (2018).

16. Yang XJ. China's Rapid Urbanization. Science 342, 310-310 (2013).

17. China-CCTV. 19:00-19:30 News video: " 40 years of reform and opening up " the transformation of innovation and stronger manufacturing power. (ed^(eds). China Central Television (2018).

18. Liu J. China's Road to Sustainability. Science 328, 50 (2010).

19. Mathews JA, Tan H. Circular economy: Lessons from China. Nature 531, 440-442 (2016). 
20. OECD. Global Material Resources Outlook to 2060. OECD Publishing (2019).

21. Zhang L, et al. Critical Mineral Security in China: An Evaluation Based on Hybrid MCDM Methods. Sustainability 10, 4114 (2018).

22. Wen Z, Zhang C, Ji X, Xue Y. Urban Mining's Potential to Relieve China's Coming Resource Crisis. Journal of Industrial Ecology 19, 1091-1102 (2015).

23. IRP. Assessing global resource use: a systems approach to resource efficiency and pollution reduction. (ed^(eds Bringezu S, et al.). United Nations Environment Programme (2017).

24. Zeng X, Gong R, Chen W-Q, Li J. Uncovering the Recycling Potential of "New" WEEE in China. Environmental Science \& Technology 50, 1347-1358 (2016).

25. van Schaik A, Reuter MA. The time-varying factors influencing the recycling rate of products. Resources, Conservation and Recycling 40, 301-328 (2004).

26. Field FR, Wallington TJ, Everson M, Kirchain RE. Strategic Materials in the Automobile: A Comprehensive Assessment of Strategic and Minor Metals Use in Passenger Cars and Light Trucks. Environmental Science \& Technology 51, 14436-14444 (2017).

27. Xue J, Hu S, Yang Q. Potentials of the Renewable Resource of Scrapped Cars in China. China Population Resources and Environment 23, 169-176 (2013).

28. Zhang Y, Yang Z, Yu X. Urban Metabolism: A Review of Current Knowledge and Directions for Future Study. Environmental Science \& Technology 49, 11247-11263 (2015).

29. Hoornweg D, Bhada-Tata P, Kennedy C. Waste production must peak this century. Nature 502, 615-617 (2013).

30. Dijst $\mathrm{M}$, et al. Exploring urban metabolism-Towards an interdisciplinary perspective. Resources, Conservation and Recycling 132, 190-203 (2018).

31. Bleischwitz $R$, et al. Resource nexus perspectives towards the United Nations Sustainable Development Goals. Nature Sustainability 1, 737-743 (2018).

32. Gerst MD, Graedel TE. In-use stocks of metals: status and implications. Environ Sci Technol 42, 7038-7045 (2008). 
33. UNEP. Metal Stocks in Society: Scientific Synthesis, A Report of the Working Group on the Global Metal Flows to the International Resource Panel (2010).

34. Restrepo E, Løvik AN, Wäger P, Widmer R, Lonka R, Müller DB. Stocks, Flows, and Distribution of Critical Metals in Embedded Electronics in Passenger Vehicles. Environmental Science \& Technology 51, 1129-1139 (2017).

35. Løvik AN, Restrepo E, Müller DB. The Global Anthropogenic Gallium System: Determinants of Demand, Supply and Efficiency Improvements. Environmental Science \& Technology 49, 5704 5712 (2015).

36. Chen WQ, Graedel TE. In-use product stocks link manufactured capital to natural capital. Proceedings of the National Academy of Sciences of the United States of America 112, 62656270 (2015).

37. Hao H, Wang H, Ouyang M, Cheng F. Vehicle survival patterns in China. Science China Technological Sciences 54, 625-629 (2011).

38. Araújo MG, Magrini A, Mahler CF, Bilitewski B. A model for estimation of potential generation of waste electrical and electronic equipment in Brazil. Waste Management 32, 335-342 (2012).

39. Li B, Yang J, Lu B, Song X. Estimation of retired mobile phones generation in China: A comparative study on methodology. Waste Management 35, 247-254 (2014).

40. Mmereki D, Li B, Wang L. Estimation of waste electronic and electrical equipment arising in Botswana-A case study of Gaborone City. International Journal of Environmental Sciences 3, 441452 (2012).

41. Matthews HS, McMichael FC, Hendrickson CT, Hart DJ. Disposition and end-of-life options for personal computers. (ed^(eds). Carnegie Mellon University Green Design Initiative Technical Report (1997).

42. Yedla S. Development of a methodology for electronic waste estimation: A material flow analysis-based SYE-Waste Model. Waste Manage Res 34, 81-86 (2016).

43. Zhang L, Yuan Z, Bi J, Huang L. Estimating future generation of obsolete household appliances in China. Waste Manage Res 30, 1160-1168 (2012).

44. Betts K. A changing e-waste equation. Environmental Science \& Technology 44, 3204-3204 (2010). 
45. Wang F, Huisman J, Stevels A, Baldé CP. Enhancing e-waste estimates: Improving data quality by multivariate Input-Output Analysis. Waste Management 33, 2397-2407 (2013).

46. Habib K, Parajuly K, Wenzel H. Tracking the Flow of Resources in Electronic Waste - The Case of End-of-Life Computer Hard Disk Drives. Environ Sci Technol 49, 12441-12449 (2015).

47. Glöser S, Soulier M, Tercero Espinoza LA. Dynamic Analysis of Global Copper Flows. Global Stocks, Postconsumer Material Flows, Recycling Indicators, and Uncertainty Evaluation. Environmental Science \& Technology 47, 6564-6572 (2013).

48. Brunner PH, Rechberger H. Handbook of Material Flow Analysis: For Environmental, Resource, and Waste Engineers, Second edn. CRC Press (2016).

49. Muller E, Hilty LM, Widmer R, Schluep M, Faulstich M. Modeling metal stocks and flows: a review of dynamic material flow analysis methods. Environ Sci Technol 48, 2102-2113 (2014).

50. Gerst MD. Linking Material Flow Analysis and Resource Policy via Future Scenarios of In-Use Stock: An Example for Copper. Environmental Science \& Technology 43, 6320-6325 (2009).

51. Duan H, Hu J, Tan Q, Liu L, Wang Y, Li J. Systematic characterization of generation and management of e-waste in China. Environ Sci Pollut Res 23, 1929-1943 (2016).

52. Sabbaghi M, Esmaeilian B, Raihanian Mashhadi A, Behdad S, Cade W. An investigation of used electronics return flows: $A$ data-driven approach to capture and predict consumers storage and utilization behavior. Waste Management 36, 305-315 (2015).

53. Gurauskienè I. The Behaviour of Consumers as One of the Most Important Factors in E-waste Problem. Environmental Research, Engineering and Management 4, 56-65 (2008).

54. Castillo E, Fernández-Canteli A. A unified statistical methodology for modeling fatigue damage. Springer (2009).

55. Zhang L, Yang J, Cai Z, Yuan Z. Understanding the Spatial and Temporal Patterns of Copper InUse Stocks in China. Environmental Science \& Technology 49, 6430-6437 (2015).

56. Weibull W. Fatigue testing and analysis of results. Pergamon Press (1961).

57. Lam CW, Lim S-R, Schoenung JM. Linking Material Flow Analysis with Environmental Impact Potential. Journal of Industrial Ecology 17, 299-309 (2013). 
58. Busch J, Steinberger JK, Dawson DA, Purnell P, Roelich K. Managing critical materials with a technology-specific stocks and flows model. Environ Sci Technol 48, 1298-1305 (2014).

59. Du X, Graedel TE. Global in-use stocks of the rare Earth elements: a first estimate. Environ Sci Technol 45, 4096-4101 (2011).

60. China-MEP. China Vehicle Environmental Management Annual Report 2016. (ed^(eds). Ministry of Environmental Protection of the People's Republic of China (2016).

61. USDOT. National Transportation Statistics: Number of U.S. Aircraft, Vehicles, Vessels, and Other Conveyances. (ed^(eds). BUREAU OF TRANSPORTATION STATISTICS (2016).

62. Tan Q, Li J, Boljkovac C. Responding to China's Waste Import Ban through a New, Innovative, Cooperative Mechanism. Environmental Science \& Technology 52, 7595-7597 (2018).

63. Brooks AL, Wang S, Jambeck JR. The Chinese import ban and its impact on global plastic waste trade. Sci Adv 4, (2018).

64. Fitzpatrick C, Olivetti E, Miller TR, Roth R, Kirchain R. Conflict Minerals in the Compute Sector: Estimating Extent of Tin, Tantalum, Tungsten, and Gold Use in ICT Products. Environmental Science \& Technology 49, 974-981 (2015).

65. Daigo I, Iwata K, Ohkata I, Goto Y. Macroscopic Evidence for the Hibernating Behavior of Materials Stock. Environ Sci Technol 49, 8691-8696 (2015).

66. Liu W, Chen LJ, Tian JP. Uncovering the Evolution of Lead In-Use Stocks in Lead-Acid Batteries and the Impact on Future Lead Metabolism in China. Environmental Science \& Technology 50, 5412-5419 (2016).

67. Sun L, Zhang C, Li J, Zeng X. Assessing the sustainability of lead utilization in China. J Environ Manage 183, 275-279 (2016).

68. Wilburn DR, Bleiwas DI. Platinum-group metals-world supply and demand. US geological survey open-file report 1224, 2004-1224 (2004).

69. Chancerel P, Marwede M, Nissen NF, Lang K-D. Estimating the quantities of critical metals embedded in ICT and consumer equipment. Resources, Conservation and Recycling 98, 9-18 (2015).

70. Kerr RA. The Coming Copper Peak. Science 343, 722-724 (2014). 
71. Nitta N, Wu F, Lee JT, Yushin G. Li-ion battery materials: present and future. Materials Today 18, 252-264 (2015).

72. Reck BK, Graedel TE. Challenges in metal recycling. Science 337, 690-695 (2012).

73. State-Council. Action plan to phase out waste imports. (ed^(eds Administration DoG) (2017).

74. McCann D, Wittmann A. Solving the E-Waste Problem (Step) Green Paper: E-waste Prevention, Take-back System Design and Policy Approaches. United Nations University/Step Initiative (2015).

75. Owens B. Mining: Extreme prospects. Nature 495, S4-S6 (2013).

76. Meinert L, Robinson G, Nassar N. Mineral Resources: Reserves, Peak Production and the Future. Resources 5, 14 (2016).

77. Reuter MA. Limits of Design for Recycling and "Sustainability": A Review. Waste Biomass Valori 2, 183-208 (2011).

78. Cullen JM, Allwood JM. Mapping the Global Flow of Aluminum: From Liquid Aluminum to EndUse Goods. Environmental Science \& Technology 47, 3057-3064 (2013).

79. Allwood JM. Chapter 30 - Squaring the Circular Economy: The Role of Recycling within a Hierarchy of Material Management Strategies. In: Handbook of Recycling (ed^(eds Worrell E, Reuter MA). Elsevier (2014).

80. Awasthi AK, Li J, Koh L, Ogunseitan OA. Circular economy and electronic waste. Nature Electronics 2, 86-89 (2019).

81. Schluep M, et al. Recycling: from E-waste to Resources. UNEP (2009).

82. Prior T, Giurco D, Mudd G, Mason L, Behrisch J. Resource depletion, peak minerals and the implications for sustainable resource management. Global Environmental Change 22, 577-587 (2012).

83. Bian Z, Miao X, Lei S, Chen SE, Wang W, Struthers S. The challenges of reusing mining and mineral-processing wastes. Science 337, 702-703 (2012). 
Acknowledgement: The work is financially supported by National Key Technology R\&D Program of China (2018YFC1900101).

Author Contributions: X. L. Z. collected data and wrote the paper; S. H.A. refined the narrative and policy analysis; J. P. T. contributed the analytical design; J. H. L supervised this study.

Supplementary Information is available in the online version of the paper: Fig. 1-17, Tables 1-14, Sections 1-4 and excel table.

Competing interests: The authors declare no competing interests. 